\title{
Rotation Equation of a Point in Air and its Solution
}

\section{Tian-Quan Yun}

School of Civil Engineering and Transportation, South China University of Technology, Wu Shan Lu 381, Tian He Qu, Guangzhou, 510641, P.R. China

Email: cttqyun@scut.edu.cn

Article History
Received: 27 January, 2022
Revised: 18 February, 2021
Accepted: 1 March, 2022
Published: 3 March, 2022
Copyright (C) 2022 ARPG
\& Author
This work is licensed under
the Creative Commons
Attribution International
(⿶) (\$) CC BY: Creative
Commons Attribution
License 4.0

Article History

Accepted: 1 March, 2022

Published: 3 March, 2022

\begin{abstract}
Operator $\boldsymbol{\nabla}$ inner products on both sides of Combination of Boyles' law and Chares law ("B-C law" in short), we got the "Wind Speed Equation of a Point in Air" ("Wind Speed Equation" in short). It suits for describing straight line motion, and It states that mu is in proportion to $\boldsymbol{\nabla} \cdot \mathrm{T}$. Operator $\boldsymbol{\nabla}$ outer products on both sides of "Wind Speed Equation" (where $\mathrm{T}$ is replaced by $\mathbf{T}$ ), we get the "Rotation Equation of a Point in Air" ("Rotation Equation" in short). It is a vector partial differential equation (PDE), suits for describing circular motion. It states that (mü) is in proportion to T. Its solution is found by method of separating variables. The existence of vector $\mathbf{T}$ is proved by the existence of rotation in atmosphere and the solution of "Rotation Equation". It reveals that the vector form of B-C law holds in rotating air. Examples of upside-down vertical rotation and horizontal rotation are given.
\end{abstract}

Keywords: Combination of Boyles' law and Chares law; Newton's second law; Rot (curl) operator; wind speed equation; $\nabla$ operator; Inner product; Outer product; Method of separating variables.

\section{Introduction}

Stirring a cup of coffee by a bar, one can make a rotation. However, there is nothing in air to stir up rotation, how can the rotation occurs? What is the locomotive driven the air to rotate? This paper answers these questions and derives a "Rotation Equation of a Point (mass) in Air" ("Rotation Equation" in short) using properties of vector product, Wind Speed Equation, and B-C law with T replaced by T. The solution of Rotation Equation is found by method of separating variables.

The straight line motion and the circular motion are two basic kinds of motion. For the straight line motion, we derived a basic formula "Wind Speed Equation of a Point in Air" [1]. Which has been confirmed by weather forecast every year and agreed with motion equation of mushroom cloud [2] derived by different assumption and scientific law.

\section{Wind Speed Equation of a Point in Air}

\subsection{Model}

A model of "zero-weighted membrane wrapping a small cube $V=d x d y d z$ of air as $d x, d y, d z \rightarrow 0$ " is used. Since the air exists in everywhere, it has no shape, no volume, and thus hard to establish an equation using scientific laws. Once the "zero-weighted model" has been used, the wrapped air has shape and volume, such that the scientific laws can be used to derive the equation, meanwhile the actually stress field has not been disturbed, since there is nothing wrapped the air.

In the following, bold face denotes vector, matrix, and tensor.

\subsection{Deriving of Wind Speed Equation}

According to combination of Boyles' law and Chares law, we have:

$$
\mathrm{pV}=\mathrm{cT} \text {, }
$$

Where $\mathrm{p}=$ pressue, accuracy $\mathbf{p}$ is a stress tensor, with the same normal stress and zero shearing stress:

$$
\mathbf{p}=\left[\begin{array}{ccc}
\sigma_{\mathrm{xx}} & 0 & 0 \\
0 & \sigma_{\mathrm{yy}} & 0 \\
0 & 0 & \sigma_{\mathrm{zz}}
\end{array}\right]=\mathrm{p}\left[\begin{array}{lll}
\mathbf{i} & \mathbf{j} & \mathbf{k}
\end{array}\right]^{\mathrm{T}},
$$

$\sigma_{\mathrm{xx}}=\sigma_{\mathrm{yy}}=\sigma_{\mathrm{zz}}=\mathrm{p}=$ compression normal stress, shearing stress $\sigma_{\mathrm{xy}}=\sigma_{\mathrm{yz}}=\sigma_{\mathrm{zx}}=0$. $\mathbf{i}, \mathbf{j}$, $\mathbf{k}$ are unit vector in Cartesian co-ordinates. $V=$ volume of a point $=d x d y d z=A_{x} d x=A_{y} d y=A_{z} d z$, with $d x, d y, d z \rightarrow 0$. 
$A_{x}, A_{y}, A_{z}$ are the cross section areas of the element (point), respectively. $c$ is a constant, $T$ is the absolute temperature.

$(2-2)$ is the matrix form of $\mathrm{p}$.

$$
\begin{gathered}
\boldsymbol{\nabla} \cdot(\mathrm{pV})=\mathbf{c} \boldsymbol{\nabla} \cdot \mathrm{T}, \\
\mathrm{pV}=\mathrm{p}[\mathbf{i}+\mathbf{j}+\mathbf{k}](\mathrm{dxdydz})=\left(\mathrm{pA}_{\mathrm{x}} \mathrm{dx}\right) \mathbf{i}+\left(\mathrm{pA}_{\mathrm{y}} \mathrm{dy}\right) \mathbf{j}+\left(\mathrm{pA}_{\mathrm{z}} \mathrm{dz}\right) \mathbf{k}= \\
\mathrm{F}_{\mathrm{x}} \mathrm{dx} \mathbf{i}+\mathrm{F}_{\mathrm{y}} \mathrm{dy} \mathbf{j}+\mathrm{F}_{\mathrm{z}} \mathrm{dzk}=\mathbf{F} \cdot \mathbf{d s},
\end{gathered}
$$

Where $\mathrm{F}=$ the applied force, $\mathbf{s}=$ the displacement,

$$
\begin{gathered}
\mathbf{F}=\mathrm{F}_{\mathrm{x}} \mathbf{i}+\mathrm{F}_{\mathrm{y}} \mathbf{j}+\mathrm{F}_{\mathrm{z}} \mathbf{k}, \\
\mathbf{s}=\mathrm{s}_{\mathrm{x}} \mathbf{i}+\mathrm{s}_{\mathrm{y}} \mathbf{j}+\mathrm{s}_{\mathrm{z}} \mathbf{k},
\end{gathered}
$$

By Newton's second law, we have

$$
\mathbf{F}=m \dot{\mathbf{u}}=\mathrm{m}\left(\dot{\mathrm{u}}_{\mathbf{x}} \mathbf{i}+\dot{\mathrm{u}}_{\mathrm{y}} \mathbf{j}+\dot{\mathrm{u}}_{\mathrm{z}} \mathbf{k}\right)
$$

Where $\mathrm{m}$ is the mass, $\mathbf{u}$ is the wind speed, $\dot{\mathbf{u}}=\partial \mathbf{u} / \partial$ t. i.e., the acceleration.

$$
\mathrm{mu}=\mathrm{c} \boldsymbol{\nabla} \cdot \mathrm{T},
$$

Substituting (2-4) - (2-7) into (2-3), we have

(2-8) is called the "Wind Speed Equation of A Point (Mass) in Air". It states that mu is in proportion to $\boldsymbol{\nabla} \cdot \mathrm{T}$. $(2-8)$ also shows that the gradient temperature is the locomotive driven wind speed acceleration along a straight line.

\subsection{Confirming of Wind Speed Equation}

Every winter, the weather forecast alerts people that cold wave strong wind companies with temperature sharp dropping. These descriptions confirms with (2-8). (2-8) is also well agreed with the result of Tian-Quan [2] derived by different model based on modifying Navier-Stock equation.

\section{Mathematical Description on Rotating Motion}

By Editor Group [3], rotation is defined by outer product (or vector product) of two vectors $\nabla$ and $s$, and is denoted by rot $\mathbf{s}$ :

$$
\begin{aligned}
& \operatorname{rot} \mathbf{s}:=\nabla \times \mathbf{s}=\left|\begin{array}{ccc}
\mathbf{i} & \mathbf{j} & \mathbf{k} \\
\frac{\partial}{\partial \mathrm{x}} & \frac{\partial}{\partial \mathrm{y}} & \frac{\partial}{\partial \mathrm{z}} \\
\mathrm{X} & \mathrm{Y} & \mathrm{Z}
\end{array}\right|=\left(\frac{\partial \mathrm{Z}}{\partial \mathrm{y}}-\frac{\partial \mathrm{Y}}{\partial \mathrm{Z}}\right) \mathbf{i}-\left(\frac{\partial \mathrm{X}}{\partial \mathrm{Z}}-\frac{\partial \mathrm{Z}}{\partial \mathrm{X}}\right) \mathbf{j}+\left(\frac{\partial \mathrm{Y}}{\partial \mathrm{X}}-\frac{\partial \mathrm{X}}{\partial \mathrm{Y}}\right) \mathbf{k}, \\
& \mathbf{s}(\mathbf{r})=\mathrm{X}(\mathrm{x}, \mathrm{y}, \mathrm{z}) \mathbf{i}+\mathrm{Y}(\mathrm{x}, \mathrm{y}, \mathrm{z}) \mathbf{j}+\mathrm{Z}(\mathrm{x}, \mathrm{y}, \mathrm{z}) \mathbf{k},
\end{aligned}
$$

Where $\mathbf{s}$ is vector function, $X(x, y, z), Y(x, y, z), Z(x, y, z)$ are components, $\nabla=\frac{\partial}{\partial x} \mathbf{i}+\frac{\partial}{\partial y} \mathbf{j}+\frac{\partial}{\partial z} \mathbf{k}$, (Hamilton or Laplace operator) is also a vector. The first row of the determinant is a unit vector $\mathbf{I}=1 \mathbf{i}+1 \mathbf{j}+1 \mathbf{k}$, the second row is the components of vector $\nabla$, the third row is the components of vector $\mathbf{s}$.

\subsection{Necessary and Sufficient Conditions for Existence of Rotation}

If

$$
\mathbf{s} \neq \mathbf{0}, \mathbf{s} \neq \mathbf{I}, \mathbf{s} \neq \boldsymbol{\nabla},
$$

then, rotation exists. And vice versa.

If vector $\mathbf{s}$ parallels to vector $\nabla$, or $\mathbf{s}$ parallels to vector I, or $\mathbf{s}=\mathbf{0}$,

$$
\begin{gathered}
\mathbf{s} \| \nabla, \text { or } \mathbf{s} \| \mathbf{I} \text {, or } \mathbf{s}=\mathbf{0}, \\
\text { i.e., } \frac{\mathrm{X}(\mathrm{x}, \mathrm{y}, \mathrm{z})}{\partial / \partial \mathrm{x}}=\frac{\mathrm{Y}(\mathrm{x}, \mathrm{y}, \mathrm{z})}{\partial / \partial \mathrm{y}}=\frac{\mathrm{Z}(\mathrm{x}, \mathrm{y}, \mathrm{z})}{\partial / \partial \mathrm{z}}, \text { or } \frac{1}{\mathrm{X}(\mathrm{x}, \mathrm{y}, \mathrm{z})}=\frac{1}{\mathrm{Y}(\mathrm{x}, \mathrm{y}, \mathrm{z})}=\frac{1}{\mathrm{Z}(\mathrm{x}, \mathrm{y}, \mathrm{z})},
\end{gathered}
$$

then, $\operatorname{Rot} \mathbf{s}=\nabla \times \mathbf{s}=\mathbf{0}$. i.e., rotation disappears.

(3-3) or (3-4) are the necessary and sufficient condition for existence of rotation . This result is obvious because that two rows are the same in the determinant.

Properties of vector calculation

$$
\begin{aligned}
& \mathbf{a}=\mathbf{b} \leftarrow \rightarrow \boldsymbol{\nabla} \times \mathbf{a}=\boldsymbol{\nabla} \times \mathbf{b}, \\
& \mathbf{a} \| \mathbf{b} \leftarrow \rightarrow \frac{a_{\mathrm{x}}}{b_{\mathrm{x}}}=\frac{\mathrm{a}_{\mathrm{y}}}{\mathrm{b}_{\mathrm{y}}}=\frac{\mathrm{a}_{\mathrm{z}}}{\mathrm{b}_{\mathrm{z}}}=\mathrm{c},
\end{aligned}
$$

\section{Deriving of Rotation Equation of a Point in Air}

A modifying B-C law,

$$
\mathrm{pV}=\mathrm{c} \mathbf{T},
$$

Operator $\boldsymbol{\nabla}$ outer (or vector) products both sides of (4-1), we have:

$$
\boldsymbol{\nabla} \times(\mathrm{pV})=\boldsymbol{\nabla} \times(\mathrm{cT}),
$$

Substituting the left hand side of (2-4) --- (2-8) into the left hand side of (4-2), we have:

$$
\boldsymbol{\nabla} \times(\mathrm{m} \dot{\mathbf{u}})=\boldsymbol{\nabla} \times(\mathrm{c} \mathbf{T})=\mathrm{c} \boldsymbol{\nabla} \times \mathbf{T},
$$

By (3-5), (4-3), we have:

$$
(\mathrm{mu})=\mathrm{c} \mathbf{T} \text {, }
$$

(4-4) is a vector PDE. It is called the "Rotation Equation of a Point in Air". It states that (mü) is in proportional to $\mathbf{T}$, where $\boldsymbol{\nabla} \times \mathbf{T} \neq \mathbf{0}$. If $\boldsymbol{\nabla} \times \mathbf{T}=\mathbf{0}$, then rotation disappears. 


\section{Solution of "Rotation Equation of a Point in Air" by Method of Separating Variables}

(4-4) is a vector PDE. It is hard to solve. Changing (4-4) to scalar function (its component form) is an easy way to solve. Rot on both sides of (4-4), we have:

$$
\operatorname{Rot}(m \dot{\mathbf{u}})=\left|\begin{array}{ccc}
\mathbf{i} & \mathbf{j} & \mathbf{k} \\
\frac{\partial}{\partial \mathrm{x}} & \frac{\partial}{\partial \mathrm{y}} & \frac{\partial}{\partial \mathrm{z}} \\
\dot{m}_{\mathrm{x}} & \mathrm{mu}_{\mathrm{y}} & \mathrm{mu}_{\mathrm{z}}
\end{array}\right|=\operatorname{Rot}(\mathrm{cT})=\left|\begin{array}{ccc}
\mathbf{i} & \mathbf{j} & \mathbf{k} \\
\frac{\partial}{\partial \mathrm{x}} & \frac{\partial}{\partial \mathrm{y}} & \frac{\partial}{\partial \mathrm{z}} \\
\mathrm{cT}_{\mathrm{x}} & \mathrm{cT}_{\mathrm{y}} & \mathrm{cT}_{\mathrm{z}}
\end{array}\right|,
$$

By (3-5), we have:

$$
\begin{aligned}
& \mathrm{mu}_{\mathrm{x}}=\mathrm{cT}_{\mathrm{x}}, \\
& \mathrm{m}_{\mathrm{y}}=\mathrm{cT}_{\mathrm{y}}, \\
& \mathrm{mu}_{\mathrm{z}}=\mathrm{cT}_{\mathrm{z}},
\end{aligned}
$$

Suppose that

$$
\begin{aligned}
& \dot{\mathrm{u}}_{\mathrm{x}}=\dot{\mathrm{a}}(\mathrm{t}) \mathrm{b}\left(\mathrm{s}_{\mathrm{x}}\right), \\
& \mathrm{T}_{\mathrm{x}}=\mathrm{e}(\mathrm{t}) \mathrm{f}\left(\mathrm{s}_{\mathrm{x}}\right),
\end{aligned}
$$

Where $\mathrm{a}(\mathrm{t}), \mathrm{b}\left(\mathrm{s}_{\mathrm{x}}\right), \mathrm{e}(\mathrm{t}), \mathrm{f}\left(\mathrm{s}_{\mathrm{x}}\right)$ are unknown continuous functions and have continuous derivatives, $\mathrm{t}$ is the time, $\mathrm{s}_{\mathrm{X}}$ is the displacement( track). Substituting (5-5), (5-6) into (5-2), and separating variables, we have:

$$
\mathrm{m} \frac{\dot{\mathrm{a}}(\mathrm{t})}{\mathrm{e}(\mathrm{t})}=\mathrm{k}=\mathrm{c} \frac{\mathrm{f}\left(\mathrm{s}_{\mathrm{x}}\right)}{\mathrm{b}\left(\mathrm{s}_{\mathrm{x}}\right)},
$$

Where $\mathrm{k}$ is a constant. For simple, let

$$
\mathrm{a}(\mathrm{t})=\mathrm{e}(\mathrm{t}), \mathrm{f}\left(\mathrm{s}_{\mathrm{x}}\right) / \mathrm{b}\left(\mathrm{s}_{\mathrm{x}}\right)=\mathrm{s}_{\mathrm{x}},
$$

then, integrating both sides, we have:

$$
\int \frac{\mathrm{a}(\mathrm{t})}{\mathrm{a}(\mathrm{t})} \mathrm{dt}=\ln \mathrm{a}(\mathrm{t})=\mathrm{s}_{\mathrm{x}} \int \mathrm{dt}+\mathrm{C}=\mathrm{cs}_{\mathrm{x}} \mathrm{t}+\mathrm{C},
$$

Where $\mathrm{C}$ is a constant, determined by initial condition, i.e.

$\mathrm{t}=0, \mathrm{a}(0)=1, \ln |1|=0, \rightarrow \mathrm{C}=0$. Then, (5-9) gives:

$$
\mathrm{a}(\mathrm{t})=\exp \left[\mathrm{s}_{\mathrm{x}} \mathrm{t}\right] \text {, }
$$

Now, the solution (5-2) has been found, i.e.,

$$
\dot{\mathrm{u}}_{\mathrm{x}}=\mathrm{m} \exp \left[\mathrm{s}_{\mathrm{x}}(\mathrm{t})\right], \mathrm{T}_{\mathrm{x}}=\mathrm{c} \exp \left[\mathrm{s}_{\mathrm{x}}(\mathrm{t})\right]
$$

The solution of (5-3) and (5-4) are similarly to (5-11). The vector form of the solution is:

$$
\begin{aligned}
& \mathrm{m} \dot{\mathbf{u}}=\mathrm{m} \exp [\mathbf{s t}]=\mathrm{c} \mathbf{T}=\mathrm{c} \exp [\mathbf{s t}], \\
& \mathbf{s}=\mathrm{s}_{\mathrm{x}} \mathbf{i}+\mathrm{s}_{\mathrm{y}} \mathbf{j}+\mathrm{s}_{\mathrm{z}} \mathbf{k}, \mathbf{T}=\mathrm{T}_{\mathrm{x}} \mathbf{i}+\mathrm{T}_{\mathbf{y}} \mathbf{j}+\mathrm{T}_{\mathrm{z}} \mathbf{k}
\end{aligned}
$$

\section{Proof of the Existence of Vector T Satisfied (4-1)}

The existence of rotation in air is a fact, which can be seen in volcano spurting and mushroom raising. By the necessary and sufficient conditions of the existence of rotation (3-3), we have:

$$
\exists(\mathrm{m} \dot{\mathbf{u}}) \neq \mathbf{0},(\mathrm{m} \dot{\mathbf{u}}) \neq \nabla,(\mathrm{m} \dot{\mathbf{u}}) \neq \mathbf{I},
$$

such that (4-3) holds.

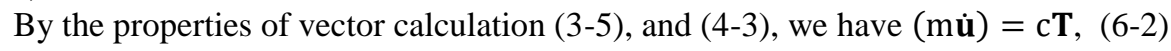

By (6-1), we have

$$
\exists(\mathrm{cT}) \neq \mathbf{0},(\mathrm{cT}) \neq \nabla,(\mathrm{cT}) \neq \mathbf{I},
$$

Such that (4-4) holds. In fact, The solution (5-12), (5-13), (5-14) shows that for $\mathbf{T}$ is holds true.

\section{Examples of Rotation in Air}

For the case of rotation existing in $\mathrm{xOy}$ plane ( the horizontal rotation surrounding to the $\mathrm{z}$-axis.

$$
\operatorname{Rot}(m \dot{\mathbf{u}})=\left|\begin{array}{ccc}
\mathbf{i} & \mathbf{j} & \mathbf{k} \\
\partial / \partial \mathrm{x} & \partial / \partial \mathrm{y} & 0 \\
\mathrm{mu}_{\mathrm{x}} & \mathrm{mu}_{\mathrm{y}} & 0
\end{array}\right|=\mathbf{k}\left|\begin{array}{cc}
\partial / \partial \mathrm{x} & \partial / \partial \partial \mathrm{y} \\
\operatorname{mi}_{\mathrm{x}} & \operatorname{mi}_{\mathrm{y}}
\end{array}\right|=\operatorname{mk}\left(\frac{\partial}{\partial \mathrm{x}} \dot{\mathrm{u}}_{\mathrm{y}}-\frac{\partial}{\partial \mathrm{y}} \dot{\mathrm{u}}_{\mathrm{x}}\right) \neq 0,
$$

(7-1) shows that the rotation exists in $\mathrm{xOy}$ plane (i.e., the horizontal plane ) surrounding the z-axis( $\mathbf{K}$ vector). Similarly, for the case of rotation existing in vertical plane (up=side-down plane) surrounding the $\mathrm{x}$-axis.

$$
\operatorname{Rot}(m \dot{\mathbf{u}})=\left|\begin{array}{ccc}
\mathbf{i} & \mathbf{j} & \mathbf{k} \\
0 & \partial / \partial \mathrm{y} & \partial / \partial \mathrm{z} \\
0 & \mathrm{mi}_{\mathrm{y}} & \mathrm{m}_{\mathrm{z}}
\end{array}\right|=\mathbf{i}\left|\begin{array}{cc}
\partial / \partial \mathrm{y} & \partial / \partial \mathrm{z} \\
\dot{m u}_{\mathrm{y}} & \operatorname{mu}_{\mathrm{z}}
\end{array}\right|=\mathrm{m}\left(\frac{\partial}{\partial \mathrm{y}} \dot{\mathrm{u}}_{\mathrm{z}}-\frac{\partial}{\partial \mathrm{z}} \dot{\mathrm{u}}_{\mathrm{y}}\right) \neq 0
$$

(7-2) shows that the rotation exists in vertical plane (up=side-down plane) surrounding the $x$-axis.

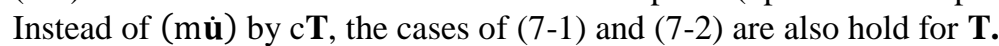

\section{Discussion}

$\mathbf{Q}=$ question, $\mathbf{A}$ = answer

Q1: Temperature $\mathrm{T}$ is a scalar or a vector?

A1: It can be a scalar, in this case, rotation disappears. It can be a vector, in this case, rotation happens.

Q2: What is the difference between temperature $\mathrm{T}$ to be a scalar and to be a vector? 
A2: If $\mathrm{T}$ is a scalar, then, $\mathrm{T}$ keeps the same value measured for different directions. If $\mathrm{T}$ is a vector, then, $\mathrm{T}$ 's value varies from different directions.

Q3: Temperature $\mathrm{T}$ is well known to be a scalar as a common sense, do you have evidence to show $\mathrm{T}$ can be a vector?

A3: Yes, volcano spurting and mushroom cloud raising are visible, one can see that rotation happens. According to the necessary and sufficient conditions of the existence of rotation (3-3), the vector (mu) $\neq 0$, $(m \dot{\mathbf{u}}) \neq \boldsymbol{\nabla},(\mathrm{m} \dot{\mathbf{u}}) \neq \mathbf{I},(4-4)$, and the solution(5-12), (5-13). (5-14). Which shows that $\mathbf{T}$ has three components, i.e., $\mathbf{T}$ is a vector.

Q4: What is/are the factor(s) caused the air rotation?

A4: Since there is nothing in air to stir up the air rotated, (mü) or cT is the factor driving the air rotated.

Q5: What is the new finding(s)?

A5: Vector T exists in air rotation. The solution of "Rotation Equation" is found. The vector form of B-C law holds. These are new findings.

Q6: Lists work(s) related to this problem.

A6: $[1,2,4-8]$.

\section{Conclusion}

Heat (measured by temperature) is the locomotive of air motion. For straight line motion, temperature is a scalar. For circular motion, temperature is a vector. The straight line motion obeys scalar form of B-C law, while, the circular motion obeys vector form of B-C law. Operator $\boldsymbol{\nabla}$ inner products (or scalar products) on both sides of scalar form of B-C law, we got "Wind Speed Equation", while operator $\boldsymbol{\nabla}$ outer products (or vector products) on both sides of "wind speed equation" (T replaced by $\mathbf{T}$ ), we get "Rotation Equation".

(4-4) states that (mü) is in proportion to $\mathbf{T}$.

The existence of vector $\mathbf{T}$ is proved by the necessary and sufficient conditions of the existence of rotation (3-3), the properties of vector calculation (3-5), and (4-3), and the solution (5-12), (5-13), (5-14), which show that $\mathbf{T}$ is a vector.

Examples of up-side-down vertical rotation and horizontal rotation are given.

\section{Data Availability Statement}

All data are cited from open publications.

\section{References}

[1] Tian-Quan, Y., 2016a. "Wind speed equation of a point in air." Fundamental Journal of Modern Physics, vol. 9, pp. 57-64.

[2] Tian-Quan, Y., 2021. "Motion equation and solution of mushroom cloud." Atmospheric and Climate Science, vol. 11, pp. 86-97. Available: https://doi.org/10.4236/acs.2021.111006

[3] Editor Group, 1979. Mathematical hand book. High Education Publishers, p. 1398.

[4] Tian-Quan, Y., 2016b. "Existence and Solution of Wind Speed Equation of A Point in Air." British Journal of Mathematics and Computer Science, vol. 17, pp. 1-5.

[5] Tian-Quan, Y., 2017a. "Wind speed equation of circular cyclone." British Journal of Mathematics and Computer Science, vol. 20, pp. 1-8.

[6] Tian-Quan, Y., 2017b. "Solution of wind speed equation of circular cyclone and its application." British Journal of Mathematics and Computer Science, vol. 21, pp. 1-13.

[7] Tian-Quan, Y., 2017c. "New dynamic equation of aerosol in air of certain type." Atmospheric and Climate Science, vol. 7, pp. 551-524.

[8] Tian-Quan, Y. and Fey, Y., 2021. Wind Speed Equation --- the base of wind description of certain type. Scholars Publisher of International Book-Market Service Ltd of Omni-Scriptum Group. 